\title{
Comparative surgical risk between type of trampoline (size and place) and type of patients (age and sex) in trampoline related injury: a systematic review and indirect meta-analysis
}

\author{
Janisa Andrea Muljadi ${ }^{1}$, Kornkit Chaijenkij ${ }^{2}$, Alisara Arirachakaran ${ }^{3}$ and Jatupon Kongtharvonskul ${ }^{4^{*}}$
}

\begin{abstract}
Background: Despite its high risk of injury, many people are still favor trampolining. However, currently there is no consensus as to which type of trampoline and which type of participant is more likely to have a trampoline related injury that will require surgical management.

Methods: This systematic review and meta-analysis aims to assess and compare the factors that cause trampoline injuries requiring surgical treatment. These include the place of the trampoline (park versus home), size of the trampoline (full versus mini), the age of the participant (child versus adult) and the sex of the participant (male versus female). The clinical outcomes measured are surgical management after trampoline injury. This systematic review was conducted according to the PRISMA guidelines.

Results: Relevant studies that reported surgery after trampoline injury of either group were identified from Medline and Scopus from inception to May 14, 2019. Sixteen studies were included for the analysis of surgery after trampoline injury; a total of 4491 and 1121 patients were treated conservatively and surgically. The total surgery rate per patient was $31 \%(95 \% \mathrm{Cl}: 16,46 \%)$ in all patients. The surgery rate was $0.3(95 \% \mathrm{Cl}: 0.03,0.58)$ and $0.06(95 \%$ Cl: $0.04,0.09)$ in the full and mini size trampoline groups. There were $0.36(95 \% \mathrm{Cl}: 0.06,0.67)$ and 0.11 (95\% Cl: 0.0 , 0.22 ) in the park and home trampoline groups. The surgery rates were 0.33 ( $95 \% \mathrm{Cl}: 0.14,0.53), 0.24$ (95\% Cl: 0.07 , $0.11), 0.49$ (95\% Cl: $0.47,0.51)$ and 0.38 (95\% Cl: $0.22,0.53)$ in children, adults, females and males respectively. Indirect meta-analysis shows that full size trampolines provided a 6.0 times higher risk of surgery $(95 \% \mathrm{Cl}: 3.7,9.7)$ when compared to mini size trampolines. Park trampolines had a higher risk of surgery of $2.17(95 \% \mathrm{Cl}: 1.70,2.78)$ when compared to home trampolines. In terms of age and sex of participants, there value was significantly higher at $1.65(95 \% \mathrm{Cl}: 1.35,2.01)$ and $1.54(95 \% \mathrm{Cl}: 1.36,1.74)$ in children compared to adults and females compared to males. From all the statistical data we summarized that the full size trampoline injuries have a 6 times higher risk of (Continued on next page)
\end{abstract}

\footnotetext{
* Correspondence: Jatupon_kong@hotmail.com

${ }^{4}$ Section for Clinical Epidemiology and Biostatistics, Faculty of Medicine Ramathibodi Hospital and Orthopedic department, Payathai3 Hospital, Bangkok, Thailand

Full list of author information is available at the end of the article
}

(c) The Author(s). 2020 Open Access This article is licensed under a Creative Commons Attribution 4.0 International License, which permits use, sharing, adaptation, distribution and reproduction in any medium or format, as long as you give appropriate credit to the original author(s) and the source, provide a link to the Creative Commons licence, and indicate if changes were made. The images or other third party material in this article are included in the article's Creative Commons licence, unless indicated otherwise in a credit line to the material. If material is not included in the article's Creative Commons licence and your intended use is not permitted by statutory regulation or exceeds the permitted use, you will need to obtain permission directly from the copyright holder. To view a copy of this licence, visit http://creativecommons.org/licenses/by/4.0/. The Creative Commons Public Domain Dedication waiver (http://creativecommons.org/publicdomain/zero/1.0/) applies to the data made available in this article, unless otherwise stated in a credit line to the data. 
(Continued from previous page)

requiring surgery when compared to mini size trampoline injuries. Park trampoline use carries a 2 times higher risk of requiring surgery when compared to home trampoline use. In terms of age and sex of the participant, there is a 1.5 times significantly higher risk of injury in children compared to adults, and females when compared to males.

Conclusion: In trampoline related injuries, full size, park trampoline, children and females had higher surgery rates when compared to mini size, home trampoline, adult and male majority in indirect meta-analysis methods.

Keywords: Trampoline, Trampoline related injury, Full or mini trampoline, Park or home, Surgery, Systematic review, Meta-analysis

\section{Background}

The first trampoline related injuries were reported in 1956 by Zimmerman [1] and in 1960 by Ellis et al. [2]. Spinal cord injuries are among the most severe injury associated with trampolines. Most of these injuries involve the cervical spine and result in quadriplegia [3-5]. The growing popularity of trampolines has caused significant increases in the number of injuries associated with their use [6]. During the period of 2000-2005, trampoline injury cases went up sharply at the rate of $113 \%$ compared to the past 5 years average [7-9]. Trampolines are very popular among children. The majority of trampoline injury patients are children, whereas the adult patients are less than 1 to $25 \%$. Most of the injuries occurred on fullsized trampolines, but home trampolines are should be commonly involved. The causes of trampoline injuries that frequently happen are collision with another person on trampoline, awkward landing and falling off from the trampoline to the ground surface or building structure. Only two previous studies $[10,11]$ explored the epidemiology risk factors associated with trampoline related injuries. First study [10] compared park with domestic trampoline injuries and the results was reported that jump parks trampoline-related injury had higher risk of fractures or dislocations and surgical interventions when compared to home trampolines. Another study [11] has reported results of mini-trampolines compared with fullsized trampolines, children compared with adults. The result shows that the use of full-sized trampolines had lower risk of injury than mini-size and young children had higher risk of injury than older. However, both studies have a small number of patients that may not be representative of trampoline-related injuries and severity of patients was determined by admission rate which is not appropriate $[10,11]$. Moreover there still no information about other epidemiology risk factor associated of trampoline related injuries. Therefore, this systematic review and meta-analysis aims to assess and compare risk of surgery related after trampoline injury between place of trampoline (park versus home), size of trampoline (full versus mini), age of participant (children versus adult) and sex of participant (male versus female majority). This information may lead to increased public awareness of the potential for serious injuries and permanently disabling outcomes for those who participate in recreational trampoline use.

\section{Methods}

Medline and Scopus databases were used to identify relevant studies published in English since the date of inception to May 14, 2019. The PubMed and Scopus search engines were used to locate studies with the following search terms: Trampoline related injury. References from the reference lists of included trials and previous systematic reviews were also explored. The review protocol has been registered at the international prospective register of systematic review (PROSPERO ID: 147234).

\section{Inclusion criteria}

Clinical studies (e.g., observational, cross-sectional, cohort or randomized controlled trial (RCT)) that reported the type of treatment, whether conservative or surgical, after trampoline-related injury were eligible if they met the following criteria:

- Reported treatment conservatively or surgically after trampoline-related injury.

- Had sufficient data to extract and pool, i.e. the reported mean, standard deviation (SD), the number of subjects according to treatments for continuous outcomes, and the number of patients according to treatment for dichotomous outcomes.

\section{Exclusion criteria}

- The reference lists of the retrieved articles were also reviewed to identify publications on the same topic. Where there were multiple publications from the same study group on the same population, the most complete and recent results were used.

- Non-English studies were excluded.

\section{Data extraction}

Two reviewers (J.M. and J.K.) independently performed data extraction using standardized data extraction forms. 
General characteristics of the study (i.e. mean age, gender, body mass, location of injury, size of trampolines, mechanism of injury (fall, collision, fell off, contact with structure, unknown), type of injury (sprain, fracture, dislocation, concussion, other), region of injury (spine, upper extremity, head, trunk, lower extremity, other), and length of hospital stay were extracted. All dichotomous outcomes (any type of surgery) were also extracted. Any disagreements were resolved by discussion and consensus with a third party (A.A.).

\section{Outcomes of interest}

The outcomes of interest included surgery or conservative treatment after trampoline injury. These outcomes were measured as reported in the original studies which were surgical (Fixation of extremity fracture, spine surgery, head and neck surgery, thoracic and abdominal surgery) and conservative (medication, casting, splint, observation) treatment which included patients who were outpatients and inpatients.

\section{Statistical analysis}

For dichotomous outcomes (surgery), the prevalence was pooled and calculated using the Mantel-Haenszel analysis method. Heterogeneity of mean differences was checked using the $\mathrm{Q}$ statistic and the degree of heterogeneity was also quantified using the $\mathrm{I}_{2}$ statistic [12]. If heterogeneity was significant or $\mathrm{I}_{2}>25 \%$, the pooled prevalence was estimated using a random effects model, otherwise a fixed effects model was applied. Metaregression analysis was then applied to explore causes of heterogeneity $[12,13]$. Coverable parameters i.e. mean age, gender, body mass, location of injury, size of trampolines, mechanism of injury (fall, collision, fell off, contact with structure, unknown), type of injury (sprain, fracture, dislocation, concussion, other), region of injury (spine, upper extremity, head, trunk, lower extremity, other), and length of hospital stay were considered in the meta-regression model. Power of the test for metaregression was also assessed [14]. The odds ratio (OR) were estimated by indirect meta-analysis using a random effects model, If heterogeneity was significant or I2 > $25 \%$, otherwise a fixed effects model was applied otherwise a fixed effects model was applied. All analyses were performed using STATA version 15.0 [15]. A $p$-value $<0.05$ was considered statistically significant, except for the test of heterogeneity where $<0.10$ was used.

\section{Results}

Seventy three and 83 studies were identified from Medline and Scopus respectively, as described in Fig. 1. Sixty-nine studies were duplicates, leaving 87 studies for review of titles and abstracts. Of these, 16 articles [10, 11, 16-29] were relevant and the full papers were retrieved.
Characteristics of these studies are described in Table 1. Seventy-one studies were deleted under exclusion criteria; $3,14,6,5,37$ and 6 studies were other intervention, no outcomes, biomechanics, review, other injuries and no English language, respectively. Sixteen studies were included for the analysis of trampoline-related injury; 14 studies [16-29] were retrospective cohort and 2 studies $[10,11]$ were comparative cohort studies. All 14 studies reported conservative and surgical management. Four studies, 2, 2, 2, 1, 1, 1, 1, 1 and 1 study were reported from America, Australia, Ireland, Korea, Denmark, Hong Kong, Canada, Austria, Finland and United Kingdom, respectively. Six and two studies were included for the analysis of full and mini size trampolines. Four studies each were included for analysis of park versus home trampolines. Thirteen studies included mostly children, and another three studies included mostly adults. Seven studies were mostly male, while 6 studies were mostly female. The lower extremities were the most common sites of injury (42\%) whereas the spine was the least common site of injury (4\%). The most common mechanism of injury was falling on the trampoline (30\%). Fractures were the most common injury (40\%) while dislocation was the least common injury (4\%). Mean age and percentages of male patients varied from 5.25 to 25 years and 37 to $71 \%$ (Table 1).

\section{Pooled prevalence of treatment (conservative and surgery) related trampoline injury}

Overall, there were 5622 patients (4233 in the conservative group and 1379 in the surgery group). The total surgical rate per patient was $0.69 \%$ (95\% CI: $0.54,0.84 \%$ ) and $0.31 \%$ (95\% CI: $0.16,0.46 \%)$ in all patients (Table 2 ).

\section{Full versus mini size trampoline}

There were a total of 739 and 402 patients in full and mini size trampoline studies. There were 187 patients in the full size group and 17 patients in the mini size group that had undergone surgery for trampoline injuries. The surgery rates per patient with injuries from full versus mini size trampolines were $0.3 \%$ (95\% CI: $0.03,0.58 \%)$ and $0.06 \%$ (95\% CI: 0.04, 0.09) (Table 3). By indirect meta-analysis, the full sized trampoline had a higher risk of requiring surgery by 6.0 (95\% CI: 3.7, 9.7) when compared to the mini sized trampoline (Fig. 2 and Table 4).

\section{Park versus home trampoline}

There were a total of 3534 and 746 patients in park and home trampoline studies, with 648 patients in the park group and 63 patients in the home group who had undergone surgery for trampoline injury. The surgery rate per patient of park and home trampolines were $0.36 \%$ (95\% CI: $0.06,0.67 \%$ ) and $0.11 \%$ (95\% CI: 0.0 , 0.22) (Table 3). By indirect meta-analysis, park trampolines had a higher risk of requiring surgery by 2.17 (95\% 


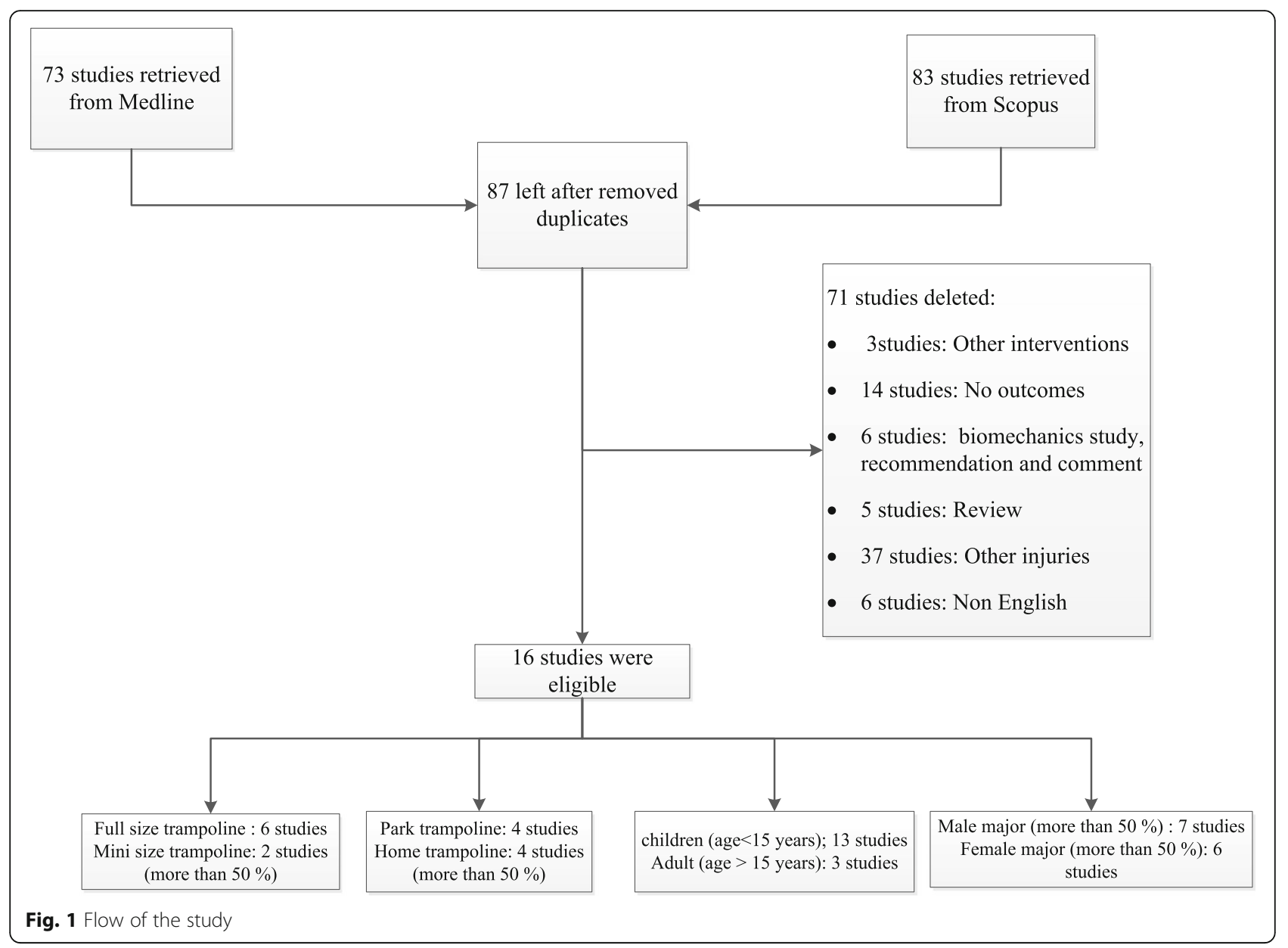

CI: $1.70,2.78)$ when compared to home trampolines (Fig. 2 and Table 4).

\section{Age and sex associated surgery}

There were a total of 4916 patients in the age group lower than 15 years of age (children) and 706 patients in the age group more than 15 years of age (adults), with 978 patients in the female group and 4009 patients in the male group. One thousand thirty-one patients in the children group and 90 patients in the adult group had undergone surgery in the trampoline injury patients. For sex, 258 patients in the male group and 687 patients in the female group had undergone surgery for trampolinerelated injury.

The surgery rate per patient of for children, adult, female and male groups were $0.33 \%$ (95\% CI: $0.14,0.53 \%$ ), $0.24 \%$ (95\% CI: 0.07, 0.11), 0.49 (95\% CI: 0.47, 0.51) and 0.38 (95\% CI: 0.22, 0.53) (Table 3). By indirect metaanalysis, children and females had a higher risk of requiring surgery by 1.65 (95\% CI: $1.35,2.01)$ and 1.54 (95\% CI: 1.36, 1.74) when compared to adult and males (Fig. 2 and Table 4).

\section{Sources of heterogeneity}

Meta-regression was applied for exploring the cause of heterogeneity by fitting a co-variable (i.e., age, percentage of female patients, mechanism of injury, site of injury, size of trampoline and place of injury), and meta-regression was applied to assess this. None of the co-variables could explain the heterogeneity.

\section{Discussion}

From the current available evidence, this systematic review and meta-analysis has shown the following: full size trampoline injuries have a 6 times higher risk of requiring surgery when compared to mini size trampoline injuries. Park trampoline use carries a 2 times higher risk of requiring surgery when compared to home trampoline use. In terms of age and sex of the participant, there is a 1.5 times significantly higher risk of injury in children compared to adults, and females when compared to males.

From previous published studies $[9,11,23,25,26,30$, 31], the American Academy of Pediatrics (AAP) issued a policy statement in 1977 recommending "that trampolines be banned from use as part of the physical 


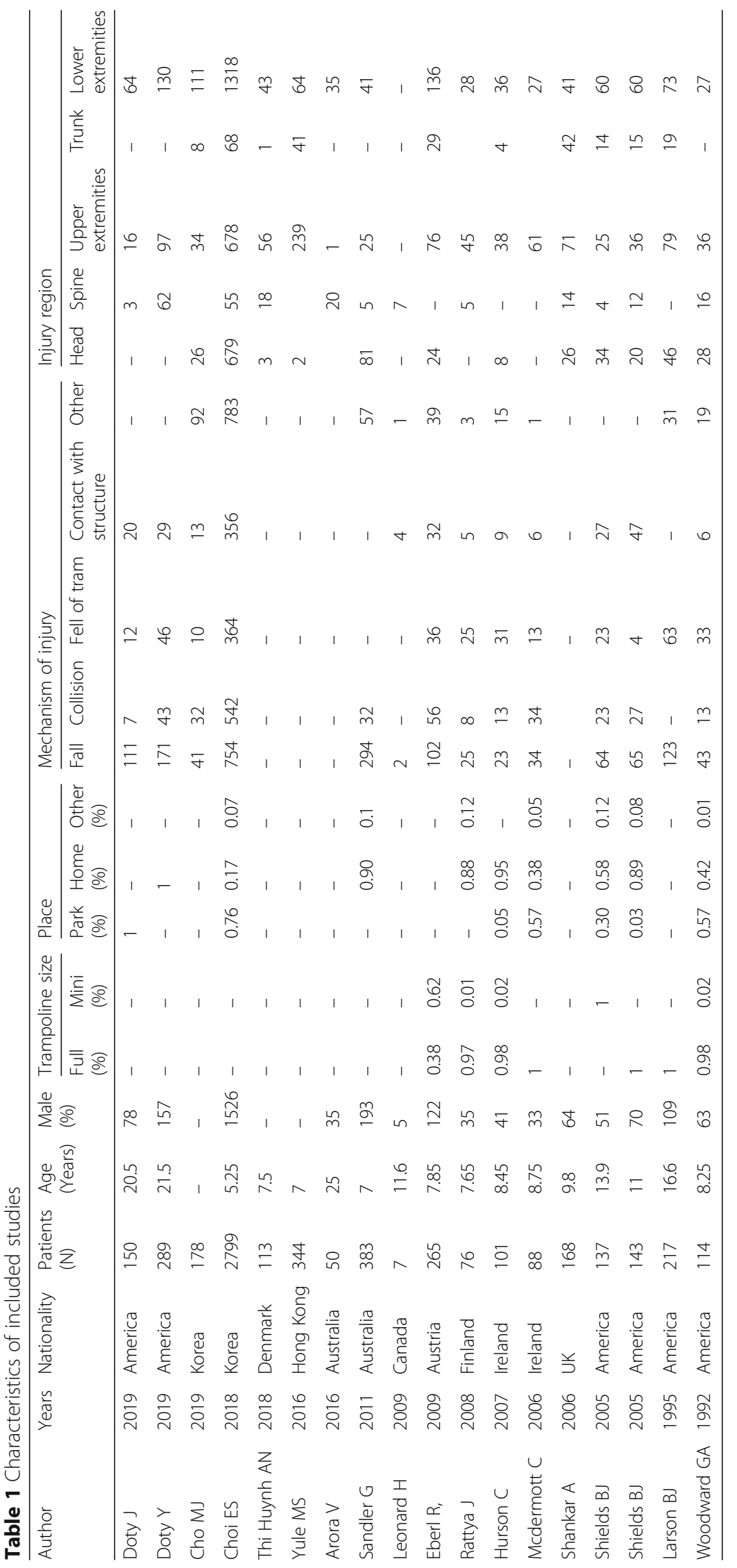


Table 2 Estimation of the pooled prevalence of treatment (conservative and surgery) related trampoline injury

\begin{tabular}{|c|c|c|c|c|c|}
\hline \multirow[t]{2}{*}{ Author } & \multirow[t]{2}{*}{ Year } & \multirow[t]{2}{*}{ Hospital stay } & \multirow[t]{2}{*}{$N$} & \multicolumn{2}{|l|}{ Treatment } \\
\hline & & & & Conservative & Surgery \\
\hline Doty J & 2019 & $6.5(7.1)$ & 150 & 131 & 19 \\
\hline Doty Y & 2019 & $1.25(0.3)$ & 289 & 269 & 20 \\
\hline Cho MJ & 2019 & - & 178 & 166 & 12 \\
\hline Choi ES & 2018 & - & 2799 & 2537 & 262 \\
\hline Thi Huynh AN & 2018 & - & 113 & 100 & 13 \\
\hline Yule MS & 2016 & - & 344 & 183 & 151 \\
\hline Arora V & 2016 & $7.3(5.8)$ & 50 & 12 & 38 \\
\hline Sandler G & 2011 & $10.2(10.8)$ & 383 & 147 & 236 \\
\hline Leonard H & 2009 & $8.1(9.0)$ & 7 & 3 & 4 \\
\hline Eberl R, & 2009 & - & 265 & 248 & 17 \\
\hline Rattya J & 2008 & $5.5(5.8)$ & 76 & 45 & 31 \\
\hline Hurson C & 2007 & $6.1(5.1)$ & 101 & 89 & 12 \\
\hline Mcdermott C & 2006 & $2.0(0.9)$ & 88 & 52 & 36 \\
\hline Shankar A & 2006 & - & 168 & 6 & 162 \\
\hline Shields BJ & 2005 & - & 137 & 137 & 0 \\
\hline Shields BJ & 2005 & - & 143 & 143 & 0 \\
\hline Larson BJ & 1995 & - & 217 & 204 & 13 \\
\hline Woodward GA & 1992 & - & 114 & 19 & 95 \\
\hline \multicolumn{4}{|c|}{ Pooled prevalence of treatment related trampoline injury $(95 \% \mathrm{Cl})$} & $0.69(0.54,0.84)$ & 0.31 (95\%Cl: $0.16,0.46)$ \\
\hline
\end{tabular}

education programs in grammar schools, high schools, and colleges, and also be abolished as a competitive sport." [31] Only three studies have reported risk factors associated with trampoline injury, with the first study reported in 2005 by Shield et al. [11], in which they reported the injury patterns were similar for mini and full sized trampolines, although mini trampoline-related injuries were less likely to require admission to the hospital. Whereas this current study has a significantly lower amount of injuries in mini-trampoline when compared to full size due to the sufficient sample size to correct the type 2 error and use conservative or surgical management to separate patients in two groups by severity of their injury (low and high severity injury) instead of admission. The second study is by Choi et al., which reported a higher number of pediatric trampoline injuries and trampoline park injuries, while ages at injury have tended to be lower, which are results that correspond with this study. Today, the widespread use of trampolines has led to a significant increase of related trauma. There, we suggest modify or additional recommendation in the policies to prevent trampoline injuries according to the results of previous published studies and this meta-analysis. Firstly, all full size and mini trampolines use should follow the policy recommendations of the American Academy of Pediatrics (AAP). Use of the mini trampoline could lower the risk of injury when compared to using full sized trampolines. Secondly, children who are aged below 15 years should be under adult supervision and always wear protection (e.g., knee pad, wrist pad and elbow pad protector) of the lower and upper extremities to prevent fracture or dislocation [9], which is the most common cause of injury requiring surgery in this study. Thirdly, jump park trampolines should be banned to lower the risk of injury then we recommend use of home trampolines. Lastly, muscle strength and proprioceptive sensation training should be done before and after jumping on the trampoline in all children to prevent injury, especially in the female sex. We want this study to be the turning point in changing the policy maker belief then the newest AAP recommendation should include the result of this systematic review in the future.

The strength of this study is that adequate methodology was used for systematic reviews in accordance with PRISMA guidelines [32] as well as providing exploration and reduction of the heterogeneity of the studies using subgroup analysis and adequate statistical analysis.

Moreover, this study has conclusive evidence about risk factors such as size, place, age and sex that should be selected to decrease risk of surgery after trampolinerelated injury. Some limitations in this study are that the number of patients \& studies was also not high. Another 
Table 3 Estimation of subgroup analysis of the pooled prevalence of treatment (conservative and surgery) related trampoline injury

\begin{tabular}{lcc}
\hline Author & Year & N \\
& & 76 \\
\hline Rattya J & 2008 & 101 \\
Hurson C & 2007 & 88 \\
Mcdermott C & 2006 & 143 \\
Shields BJ, & 2005 & 217 \\
Larson BJ & 1995 & 265 \\
Pooled prevalence of treatment related full size trampoline injury (95\% Cl) & \\
Eberl R, & 2009 & 137 \\
Shields BJ & 2005 &
\end{tabular}

Pooled prevalence of treatment related mini size trampoline injury $(95 \% \mathrm{Cl})$

Doty J

Choi ES

$$
2019
$$

$$
2018
$$

Mcdermott $C$

$$
2006
$$

Woodward GA

$$
1992
$$

\section{0}

Pooled prevalence of treatment related park trampoline injury $(95 \% \mathrm{Cl})$

Doty J

Rattya J

2019

Hurson C

Shields BJ

Shields BJ

Pooled prevalence of treatment related home trampoline injury $(95 \% \mathrm{Cl})$

Cho M.

Choi ES

Thi Huynh AN

Yule MS

Sandler G

Leonard $\mathrm{H}$

Eberl R

Rattya J

Hurson C

Mcdermott C

Shankar A

Shields BJ

Shields BJ

Woodward GA

Pooled prevalence of treatment of children related trampoline injury $(95 \% \mathrm{Cl})$

$\begin{array}{lll}\text { Doty J } & 2019 & 150 \\ \text { Doty J } & 2019 & 289 \\ \text { Arora V } & 2016 & 50 \\ \text { Larson BJ } & 1995 & 217\end{array}$

Pooled prevalence of treatment of adult related trampoline injury $(95 \% \mathrm{Cl})$ Eberl R,

Rattya J

2009

Hurson C

Mcdermott C

2008

2007

Shankar A

Shields BJ

Shields BJ

Pooled prevalence of treatment of female related trampoline injury $(95 \% \mathrm{Cl})$ Doty J
2019

150

\begin{tabular}{ll} 
Treatment & Surgery \\
\hline Conservative & 31 \\
45 & 12 \\
89 & 36 \\
52 & 0 \\
143 & 13 \\
204 & $\mathbf{0 . 3}$ (95\% Cl: 0.03, 0.58) \\
$\mathbf{0 . 7 0}(\mathbf{9 5 \%}$ Cl: 0.42, 0.97) & 17 \\
248 & 0 \\
137 & $\mathbf{0 . 0 6}$ (95\% Cl:0.04, 0.09) \\
$\mathbf{0 . 9 4}(\mathbf{9 5} \%$ Cl: 0.91, 0.97) & 19 \\
131 & 262 \\
2537 & 36 \\
52 & 95
\end{tabular}

0.64 (95\% Cl: $0.33,0.94)$

$0.36(95 \% \mathrm{Cl}: 0.06,0.67)$

269

45

89

137

143

0.89 (95\% Cl: $0.78,1.00)$

166

2537

100

183

147

3

248

45

89

52

6

137

143

19

0.67 (95\% Cl: $0.47,0.86$ )

131

269

12

204

0.76 (95\% Cl: $0.62,0.91)$

248

45

89

52

6

137

143

0.51 (95\% Cl: $0.49,0.53)$

131
20

31

0

0

0.11 (95\% Cl: $0.0,0.22$ )

12

262

13

151

236

4

17

31

12

36

162

0

95

0.33 (95\% Cl: $0.14,0.53)$

20

38

13

0.24 (95\% Cl: $0.07,0.11)$

17

31

12

36

162

0

0.49 (95\% Cl: $0.47,0.51)$

19 
Table 3 Estimation of subgroup analysis of the pooled prevalence of treatment (conservative and surgery) related trampoline injury (Continued)

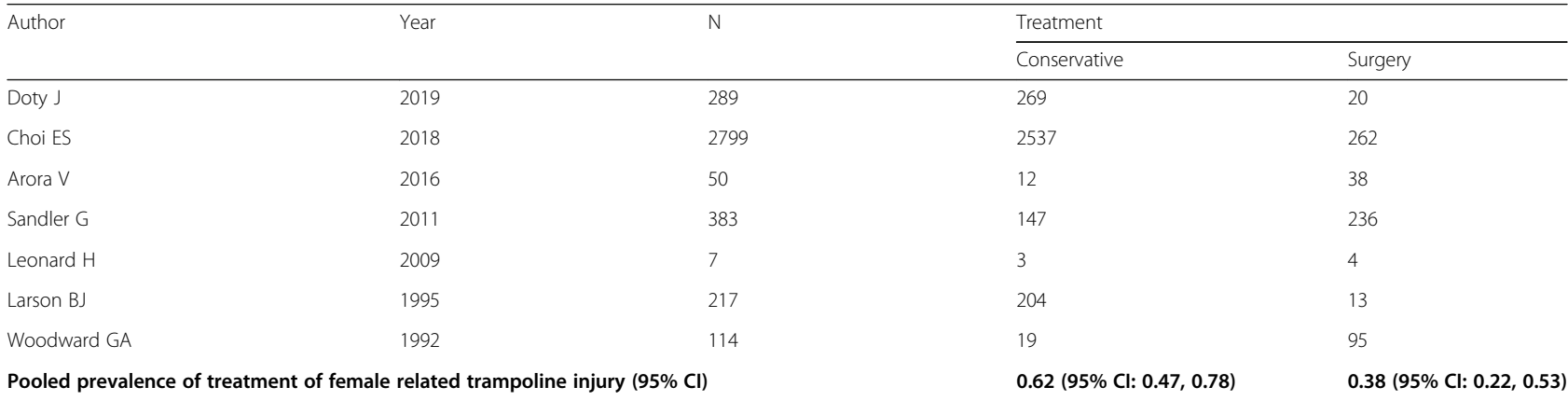

limitation is this study did not pool an important outcome such as frequency of using trampoline and injury rates with multiple users on the trampoline at the same time due to the fact that there was insufficient data. Further research that assesses a larger sample size of RCTs should be done to see any significance of complications.

\section{Conclusions}

In trampoline-related injury, full size and park trampolines, children and females had higher surgery rates when compared to mini size and home trampolines, adults and males with indirect meta-analysis methods. This result recommended use of the mini trampoline
Place

Study

ID

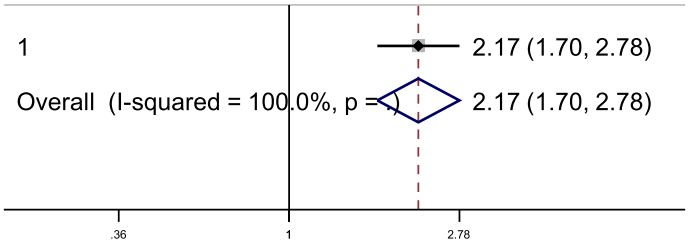

Sex

Study

ID

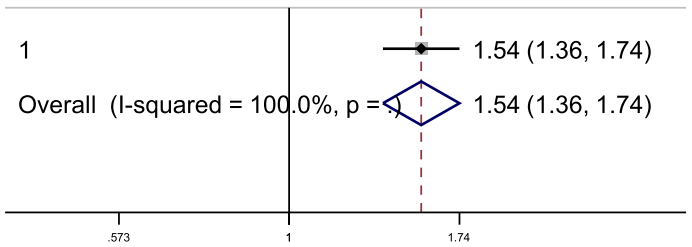

Size

Study

ID $\mathrm{RR}(95 \% \mathrm{Cl})$

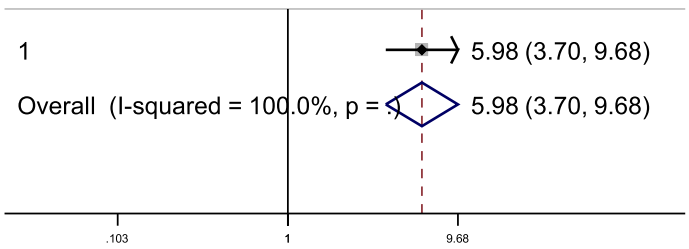

Age

Study

ID $\mathrm{RR}(95 \% \mathrm{Cl})$

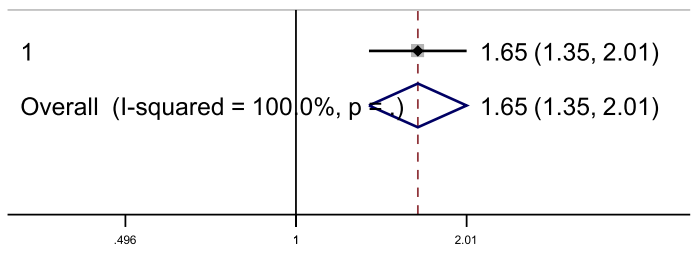

Fig. 2 Comparison of prevalence of trampoline related surgery between place of trampoline, size of trampoline, sex and age of injury participants 
Table 4 Comparisons of prevalence of surgery in trampoline related injury between full and mini size, park and home, children and adult, female and male majority

\begin{tabular}{|c|c|c|c|c|c|c|}
\hline \multirow[t]{3}{*}{ Author } & \multicolumn{4}{|l|}{ Surgical risk } & \multirow[t]{3}{*}{ OR } & \multirow[t]{3}{*}{$95 \% \mathrm{Cl}$} \\
\hline & \multicolumn{2}{|l|}{ Full size } & \multicolumn{2}{|l|}{ Mini size } & & \\
\hline & Conservative & Surgery & Conservative & Surgery & & \\
\hline \multirow[t]{3}{*}{ Pooled study } & 552 & 187 & 385 & 17 & 6.0 & $3.7,9.7$ \\
\hline & Park & & Home & & & \\
\hline & conservative & surgery & conservative & surgery & & \\
\hline \multirow[t]{3}{*}{ Pooled study } & 2886 & 648 & 683 & 63 & 2.17 & $1.70,2.78$ \\
\hline & Children & & adult & & & \\
\hline & conservative & surgery & conservative & surgery & & \\
\hline \multirow[t]{3}{*}{ Pooled study } & 3875 & 1031 & 616 & 90 & 1.65 & $1.35,2.01$ \\
\hline & \multicolumn{2}{|c|}{ Female majority } & \multicolumn{2}{|c|}{ Male majority } & & \\
\hline & conservative & surgery & conservative & surgery & & \\
\hline Pooled study & 720 & 258 & 3322 & 687 & 1.54 & $1.36,1.74$ \\
\hline
\end{tabular}

could lower the risk of injury, children should be under adult supervision and always wear protection to prevent lower and upper extremities injury, Jump park trampolines should be banned and only of home trampolines should be used. Prospective randomized controlled studies are needed to confirm these findings as the current literature is still insufficient.

\section{Abbreviations}

PRISMA: Preferred Reporting Items for Systematic Reviews and MetaAnalyses; RCT: randomized controlled trial; SD: standard deviation; OR: odds ratio; AAP: American Academy of Pediatrics

\section{Acknowledgements}

Not applicable.

\section{Authors' contributions}

All authors have read and approved the manuscript. JM: conception and design, analysis and interpretation of the data, drafting of the article, critical revision of the article for important intellectual content, final approval of the article, collection and assembly of data. KC: conception and design, drafting of the article, critical revision of the article for important intellectual content, final approval of the article. AA: conception and design, drafting of the article, critical revision of the article for important intellectual content, final approval of the article, collection and assembly of data. JK: conception and design, analysis and interpretation of the data, drafting of the article, critical revision of the article for important intellectual content, final approval of the article, collection and assembly of data.

\section{Funding}

This study has no funding support.

\section{Availability of data and materials}

All data generated or analyzed during this study are included in this published article.

\section{Ethics approval and consent to participate}

This article does not contain any studies with human participants performed by any of the authors.

\section{Consent for publication}

Not applicable.

\section{Competing interests}

All authors declare that they have no conflicts of interests.

\section{Author details}

${ }^{1}$ Mater Dei School, Bangkok, Thailand. ${ }^{2}$ Orthopedic department, College of Sports Science and Technology, Mahidol University, Bangkok, Thailand. ${ }^{3}$ Orthopedics Department, Bumrungrad Hospital, Bangkok, Thailand. ${ }^{4}$ Section for Clinical Epidemiology and Biostatistics, Faculty of Medicine Ramathibodi Hospital and Orthopedic department, Payathai3 Hospital, Bangkok, Thailand.

Received: 20 September 2019 Accepted: 3 June 2020

Published online: 06 July 2020

\section{References}

1. Zimmerman HM. Accident experience with trampolines. Res Q. 1956;27: 452-5.

2. Ellis WG, Green D, Holzaepfel NR, Sahs AL. The trampoline and serious neurological injuries. Jama. 1960;174:1673-7.

3. Torg JS. Trampoline-induced quadriplegia. Clin Sports Med. 1987;6(1):73-85.

4. Rapp GF, Nicely PG. Trampoline injuries. Am J Sports Med. 1978;6(5):260-71.

5. Kravitz H. Problems with the trampoline: I. too many cases of permanent paralysis. Pediatr Ann. 1978;7(10):728-9.

6. Briskin S, LaBotz M. Trampoline safety in childhood and adolescence. Pediatrics. 2012;130(4):774-9.

7. $\quad$ Esposito PW. Trampoline injuries. Clin Orthop Relat Res. 2003:409:43-52.

8. Hartmann KE, Calikoglu MG. Trampoline-related injuries to children. Pediatrics. 1999:103(6 Pt 1):1311-2 author reply 2-3.

9. Furnival RA, Street KA, Schunk JE. Too many pediatric trampoline injuries. Pediatrics. 1999:103(5):e57.

10. Doty J, Voskuil R, Davis C, Swafford R, Gardner W 2nd, Kiner D, et al. Trampoline-related injuries: a comparison of injuries sustained at commercial jump parks versus domestic home trampolines. J Am Acad Orthopaedic Surg. 2019;27(1):23-31.

11. Shields BJ, Fernandez SA, Smith GA. Comparison of minitrampoline- and full-sized trampoline-related injuries in the United States, 1990-2002. Pediatrics. 2005;116(1):96-103.

12. Higgins JP, Thompson SG. Quantifying heterogeneity in a meta-analysis. Stat Med. 2002:21(11):1539-58.

13. Thompson SG, Higgins JP. How should meta-regression analyses be undertaken and interpreted? Stat Med. 2002;21(11):1559-73.

14. Simmonds MC, Higgins JP. Covariate heterogeneity in meta-analysis: criteria for deciding between meta-regression and individual patient data. Stat Med. 2007;26(15):2982-99.

15. StataCorp. Stata 14 base reference manual. College Station: Stata Press; 2014.

16. Cho MJ, Kim J, Kim SJ, Kyoung KH, Keum MA, Park SK. Rapidly growing pediatric trampoline-related injuries in Korea: a 10-year single center retrospective study. Korean J Pediatrics. 2019;62(3):90-4.

17. Choi ES, Jang JH, Woo JH. Pediatric Trampoline-Related Injuries in a Nationwide Registry in South Korea, 2011 to 2016. 2018;59(8):989-94. 
18. Thi Huynh AN, Andersen MM, Petersen P, Hansen TB, Kirkegaard H, Weile JB Childhood trampoline injuries. Dan Med J. 2018;65(11):A5512.

19. Yule MS, Krishna S, Rahiri JL, Hill AG. Trampoline-associated injuries are more common in children in spring. New Zealand Med J. 2016;129(1436):37-43.

20. Arora V, Kimmel LA, Yu K, Gabbe BJ, Liew SM, Kamali MA. Trampoline related injuries in adults. Injury. 2016;47(1):192-6.

21. Sandler G, Nguyen L, Lam L, Manglick MP, Soundappan SS, Holland AJ. Trampoline trauma in children: is it preventable? Pediatr Emerg Care. 2011; 27(11):1052-6.

22. Leonard H, Joffe AR. Children presenting to a Canadian hospital with trampolinerelated cervical spine injuries. Paediatr Child Health. 2009;14(2):84-8.

23. Eberl R, Schalamon J, Singer G, Huber SS, Spitzer P, Hollwarth ME. Trampoline-related injuries in childhood. Eur J Pediatr. 2009;168(10):1171-4.

24. Rattya J, Serlo W. Using a safety net and following the safety instructions could prevent half the paediatric trampoline injuries. Eur J Pediatric Surg. 2008;18(4):261-5.

25. Hurson C, Browne K, Callender O, O'Donnell T, O'Neill A, Moore DP, et al. Pediatric trampoline injuries. J Pediatr Orthop. 2007;27(7):729-32.

26. McDermott C, Quinlan JF, Kelly IP. Trampoline injuries in children. J Bone Joint Surg Bri Vol. 2006;88(6):796-8.

27. Shankar A, Williams K, Ryan M. Trampoline-related injury in children. Pediatr Emerg Care. 2006;22(9):644-6.

28. Larson BJ, Davis JW. Trampoline-related injuries. J Bone Joint Surg Am. 1995; 77(8):1174-8.

29. Woodward GA, Furnival R, Schunk JE. Trampolines revisited: a review of 114 pediatric recreational trampoline injuries. Pediatrics. 1992;89(5 Pt 1):849-54.

30. American Academy of Pediatrics. Committee on injury and poison prevention and committee on sports medicine and fitness. Trampolines at home, school, and recreational centers. Pediatrics. 1999;103(5 Pt 1):1053-1056.

31. American Academy of Pediatrics. Committee on Accident and Poison Prevention and Committee on Pediatric Aspects of Physical Fitness, Recreation, and Sports. Skateboard policy statement. Pediatrics. 1979;63(6): 924-925.

32. Liberati A, Altman DG, Tetzlaff J, Mulrow C, Gotzsche PC, loannidis JP, et al. The PRISMA statement for reporting systematic reviews and meta-analyses of studies that evaluate health care interventions: explanation and elaboration. PLoS Med. 2009;6(7):e1000100.

\section{Publisher's Note}

Springer Nature remains neutral with regard to jurisdictional claims in published maps and institutional affiliations.

Ready to submit your research? Choose BMC and benefit from:

- fast, convenient online submission

- thorough peer review by experienced researchers in your field

- rapid publication on acceptance

- support for research data, including large and complex data types

- gold Open Access which fosters wider collaboration and increased citations

- maximum visibility for your research: over $100 \mathrm{M}$ website views per year

At $\mathrm{BMC}$, research is always in progress.

Learn more biomedcentral.com/submissions 